\title{
The GDP Growth-Rates Of Countries With The Highest Production Of Patents
}

Rolando Pena-Sanchez, Ph.D., Texas A\&M International University, USA

\begin{abstract}
The generation of patents reflects a significant part of the economical development of a country, and is an activity that is intrinsically related to the intellectual capital of an organization. This article focuses on the relationship between the growth rate of the gross domestic product (GDP) and the production of patents, based on annual data during the period 2005-2010 for the three countries around the world with the highest level in production of patents: USA, China, and Japan. A nonparametric correlation method (named Spearman's rank correlation) was selected (whose justification is explained) to estimate the correlation coefficient ( $p$-value<0.01); an economical variable: the external debt measured in US\$ billions was incorporated in the analysis, due to its significant correlation ( $p$-value $<0.01$ ), which since 2004 has been growing and reaching an unsuspected upper extreme margin.
\end{abstract}

Keywords: GDP Growth Rate; Production of Patents; External Debt; Spearman's Correlation Coefficient

\section{INTRODUCTION}

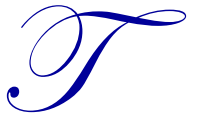

he production of patents can be viewed as a process that provides successful strategies to promote new standards in economic development; the patent represents a structure to protect the intellectual property. The business organizations and/or enterprises from countries with low-income economies are facing another challenge to their competitiveness through an invasion of technology originated from countries like United States of America (USA), China and Japan, whose leadership in the generation of patents is present in this period of global competence.

Technology has always been the changing force for mankind (Close, Humphrys and Ruttenbur 2000); The main factors affecting the production of patents are the governmental policies (non-bureaucratic decisions that reflect allocating resources (grants) to support research; which depend on economical variables like country's GDP, external debt, ), the technological tools (computer labs, physical, chemical and biological labs, networking infrastructure, etc.) and as well as the social environment (collegiality, collaboration and culture of the people doing (and/or supporting or advising) research; where the intellectual capital represents the knowledge of the researchers or investigators that are responsible of the research projects.

Talking about how the economical variables affect the generation of patents, the price of a foreign currency in dollars (the dollar-foreign currency exchange rate) is determined by U.S. demand for a foreign country goods and the foreign country demand for U.S. goods (patented merchandise). However, when the exchange rate changes that affects the price of each country's goods. That price change affects each country's demand for the other's goods in ways that tend to reverse the initial trend. This mechanism depends on floating exchange rates. If exchange rates are not permitted to respond to the forces of supply and demand, these automatic adjustments cannot occur. Given the high levels of international trade in the world today, and the "managed float" nature of exchange rates, the economies of most nations may be intertwined in various ways.

The United States has run a merchandise trade deficit since 1976, although it typically runs a surplus in services. The merchandise trade deficit rose from $\$ 36$ billion in 1982 to a peak of $\$ 160$ billion in 1987. In the recession year of 1991, the trade deficit stood at $\$ 71$ billion, but the run-up during the 1990s was particularly robust. During that period, the United States enjoyed a dynamic economic expansion while the economies of Europe and 
Asia were weakened. By 2000, the merchandise trade deficit had grown to $\$ 434$ billion. In 2001, which included three quarters of contraction, the trade deficit still reached $\$ 358$ billion; later on from 2002 to 2006 the trade deficit exhibited a decreasing behavior, with an increasing performance during 2009 after some ups and downs monthly movements in 2007-2008; but recently the deficit increased from \$41.9 billion (revised) in June-2012 to \$42.0 billion in July-2012, which is shown in Figure 1.

\section{Balance on Goods and Services Trade [Monthly, seasonally adjusted]}

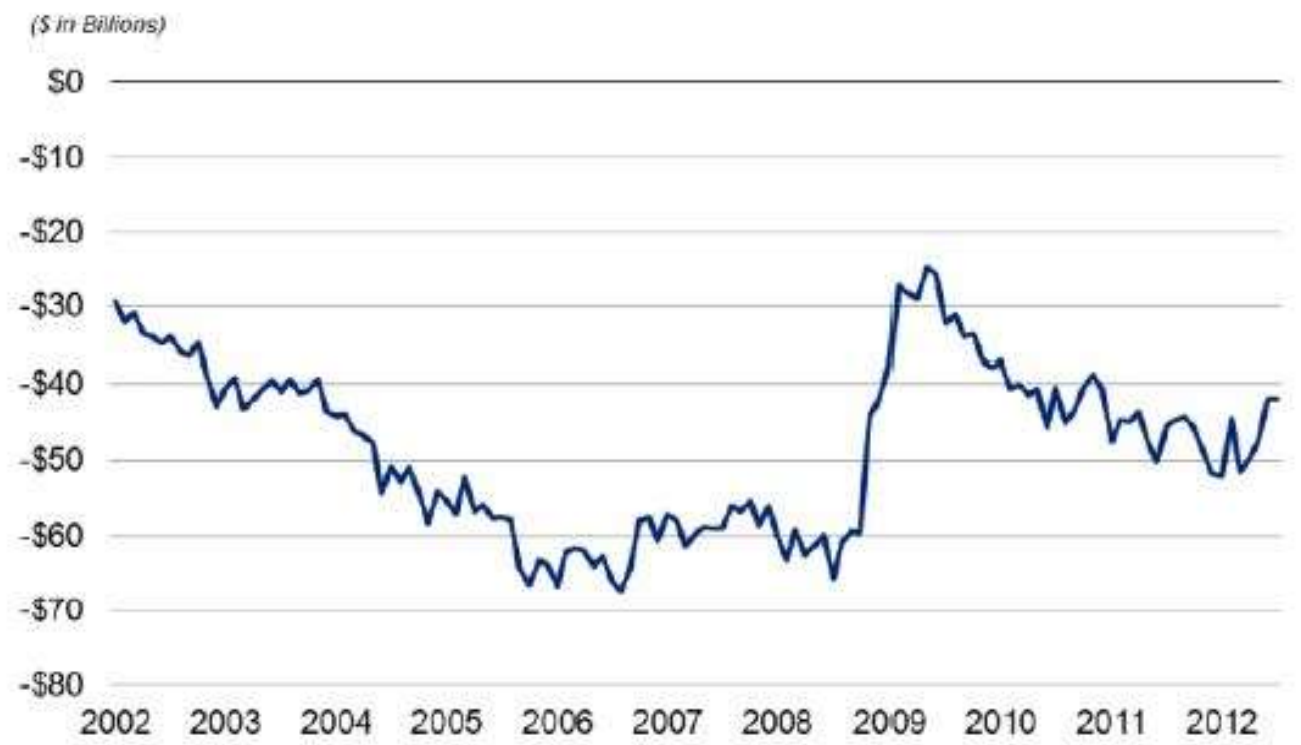

\section{Figure 1}

U.S. Trade Deficit Since 2002

Source: http://blog.bea.gov/tag/trade-deficit-2/

A very singular economical variable: the external debt measured in US\$ billions was incorporated in the analysis, due to its different statistical behavior (largest dispersion) and its high correlation.

With respect to technological tools, for example: Cisco Systems, one of the largest corporations of eLearning users, describes its compromise with the e-Learning's components; whose "components" can include content delivery in multiple formats, management of the learning experience, and a networked community of learners (online-learning), content developers and experts (intellectual capital); where e-Learning provides faster learning at reduced costs, increased access to learning, and clear accountability for all participants in the learning process.

In today's fast-paced culture (social environment) organizations that implement e-Learning provide their work force with the ability to turn change into an advantage (Kirschner and Paasa, 2001). In this context the differences between e-Learning, and online-learning should be noted: e-Learning represents the whole category of technology-based learning, while online-learning is synonymous with web-based learning; in order to be more precisely, online-learning is in fact a component of e-Learning. Thus, we can sketch a definition of e-Learning as a delivery process of knowledge, through different electronic media technologies including internet (Pena-Sanchez, 2010), intranet (Clyde, 1999), extranet, satellite broadcast, audio/video tape, interactive TV, CD ROM, etc.

Excellence in e-Learning helps us increase access to training and ensure that it is immediately relevant and cost-effective. Some advantages of online-learning include: Anywhere, Anytime, Anyone: e-Learning is available 
24 hours a day, around the world. Organizations can distribute training and important information (Glauser, 1984) to multiple locations easily and conveniently, allowing employees to access training at their convenience.

Since geographical and time barriers are virtually removed, e-Learning is no longer limited to a few people who can travel to a seminar or conference. e-Learning can occur throughout organizations and e-collaborative individuals, accelerating the transfer of knowledge (intellectual capital), and transforming learning from an isolated example of qualified development into a powerful tool for managerial decisions.

\section{OBJECTIVE}

The main objective of this article is to evaluate the linear correlation between the growth rate of gross domestic product (GDP) and the growth rate of production of patents for the three countries with the highest level in production of patents: USA, China and Japan, based on annual data during the period 2005-2010.

\section{RESEARCH HYPOTHESIS}

There is a significant correlation between the GDP growth rates and the growth rates of the number of patents among the countries with the highest production of patents during the period 2005-2010.

$\mathrm{H}_{1}: \rho \neq 0$

Thus, the correspondent null hypothesis can be specified as

$\mathbf{H}_{0}: \rho=0$

Calculating Percent Growth Rate: The percent change from one period to another is calculated from the formula:

$\mathrm{GR}=\left[\left(\mathrm{V}_{\text {Present }}-\mathrm{V}_{\text {Past }}\right) / \mathrm{V}_{\text {Past }}\right] \cdot 100(3)$

Source: http://www.ehow.com/how 4532706 calculate-growth-rate-percent-change.htm

Where, GR is the Growth Rate measured in percent

$V_{\text {Present }}$ is the Present value or the value at end of period

$\mathrm{V}_{\text {Past }}$ is the Past value or the value at beginning of period

\section{DATA, METHODOLOGY AND RESULTS}

This research is supported by secondary type data from various sources: journal articles and technical reports, such as the publications from the World Intellectual Property Organization (WIPO).

Table 1

Number of Patents Resident Regional Applications per Country, 2005-2010

\begin{tabular}{|l|c|c|c|c|c|c|}
\hline \multirow{2}{*}{ Country } & \multicolumn{6}{|c|}{ Year } \\
\cline { 2 - 7 } & $\mathbf{2 0 0 5}$ & $\mathbf{2 0 0 6}$ & $\mathbf{2 0 0 7}$ & $\mathbf{2 0 0 8}$ & $\mathbf{2 0 0 9}$ & $\mathbf{2 0 1 0}$ \\
\hline USA & 207,867 & 221,784 & 241,347 & 231,588 & 224,912 & 241,977 \\
\hline China & 93,485 & 122,318 & 153,060 & 194,579 & 229,096 & 293,066 \\
\hline Japan & 367,960 & 347,060 & 333,408 & 330,110 & 295,315 & 290,081 \\
\hline
\end{tabular}

Source: http://www.wipo.int/ipstats/en/wipi/ 
Table 2

Patents Production Growth Rate (\%) per Country, 2006-2010

\begin{tabular}{|l|c|c|c|c|c|}
\hline \multirow{3}{*}{ Country } & \multicolumn{5}{|c|}{ Year* } \\
\cline { 2 - 6 } & $\mathbf{2 0 0 6}$ & $\mathbf{2 0 0 7}$ & $\mathbf{2 0 0 8}$ & $\mathbf{2 0 0 9}$ & $\mathbf{2 0 1 0}$ \\
\hline USA & 6.70 & 8.82 & -4.04 & 17.88 & 7.59 \\
\hline China & $\mathbf{3 0 . 8 4}$ & 25.13 & 27.13 & -10.54 & 27.92 \\
\hline Japan & -5.68 & -3.93 & -0.99 & -1.77 \\
\hline
\end{tabular}

*The Annual Growth Rate for year 2005 depends on 2004, which is not available.

Table 3

GDP Growth Rate (\%) per Country, 2006-2010

\begin{tabular}{|l|c|c|c|c|c|}
\hline \multirow{3}{*}{ Country } & \multicolumn{5}{|c|}{ Year } \\
\cline { 2 - 6 } & $\mathbf{2 0 0 6}$ & $\mathbf{2 0 0 7}$ & $\mathbf{2 0 0 8}$ & $\mathbf{2 0 0 9}$ & $\mathbf{2 0 1 0}$ \\
\hline USA & 3.2 & 2.0 & 1.1 & 9.1 & 2.8 \\
\hline China & 10.2 & 11.9 & 9.0 & -5.2 & 10.3 \\
\hline Japan & 2.2 & 2.0 & -0.7 & 3.9 \\
\hline
\end{tabular}

Source: http://www.indexmundi.com/g/g.aspx?v=66\&c=us\&l=en

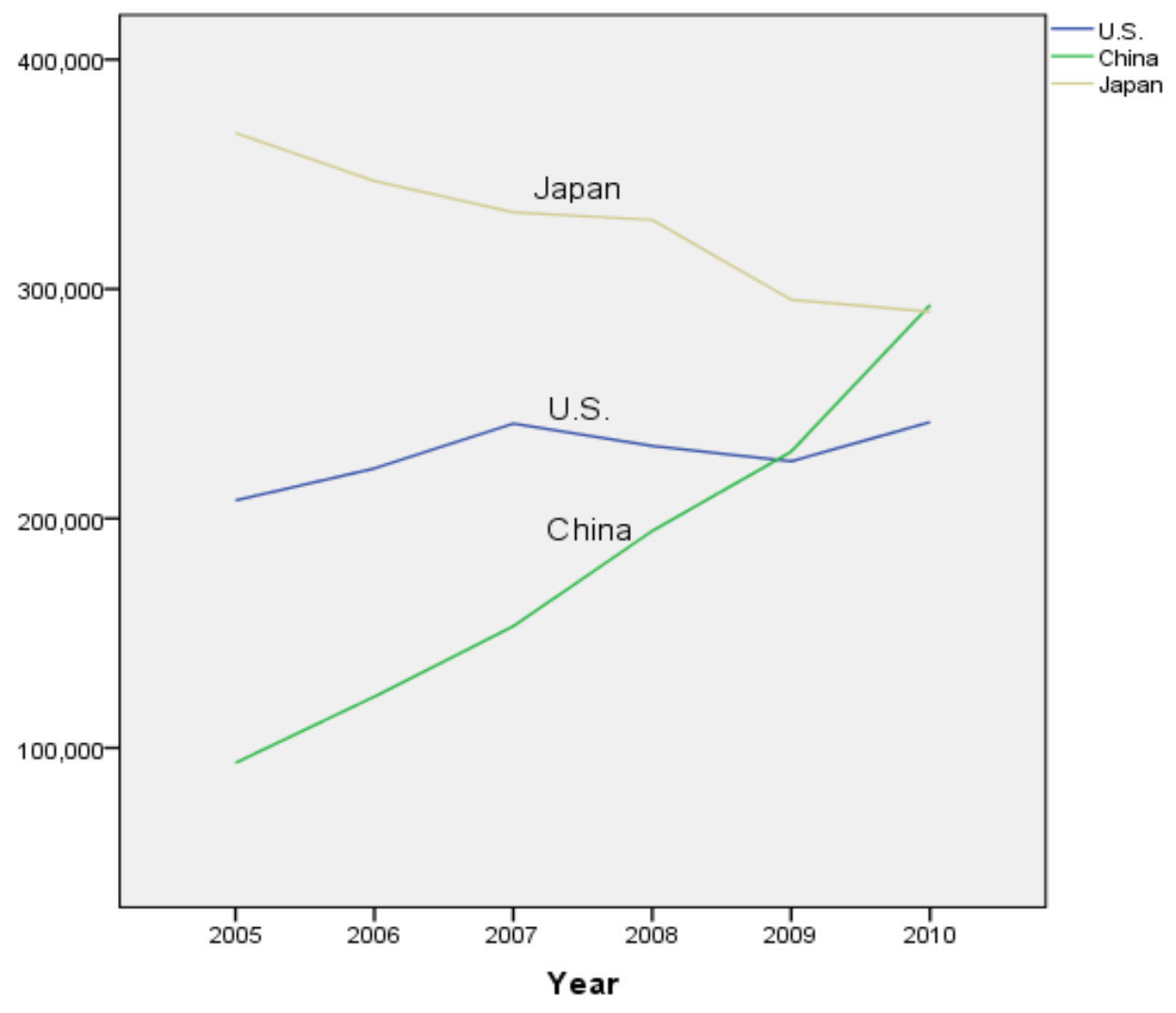

Figure 2

Production of Patents per Country, 2005-2010

From Table 1, for the year 2006 in the case of China, its percent annual growth rate was calculated according to the formula previously described:

China $\mathrm{GR}_{2006}=\left[\left(\mathrm{V}_{2006}-\mathrm{V}_{2005}\right) / \mathrm{V}_{2005}\right] \cdot 100$

China $\mathrm{GR}_{2006}=[(122,318-93,485) / 93,485] \cdot 100$

China $\mathrm{GR}_{2006}=30.84$

An identical procedure was used to calculate all the values in Table 2. 


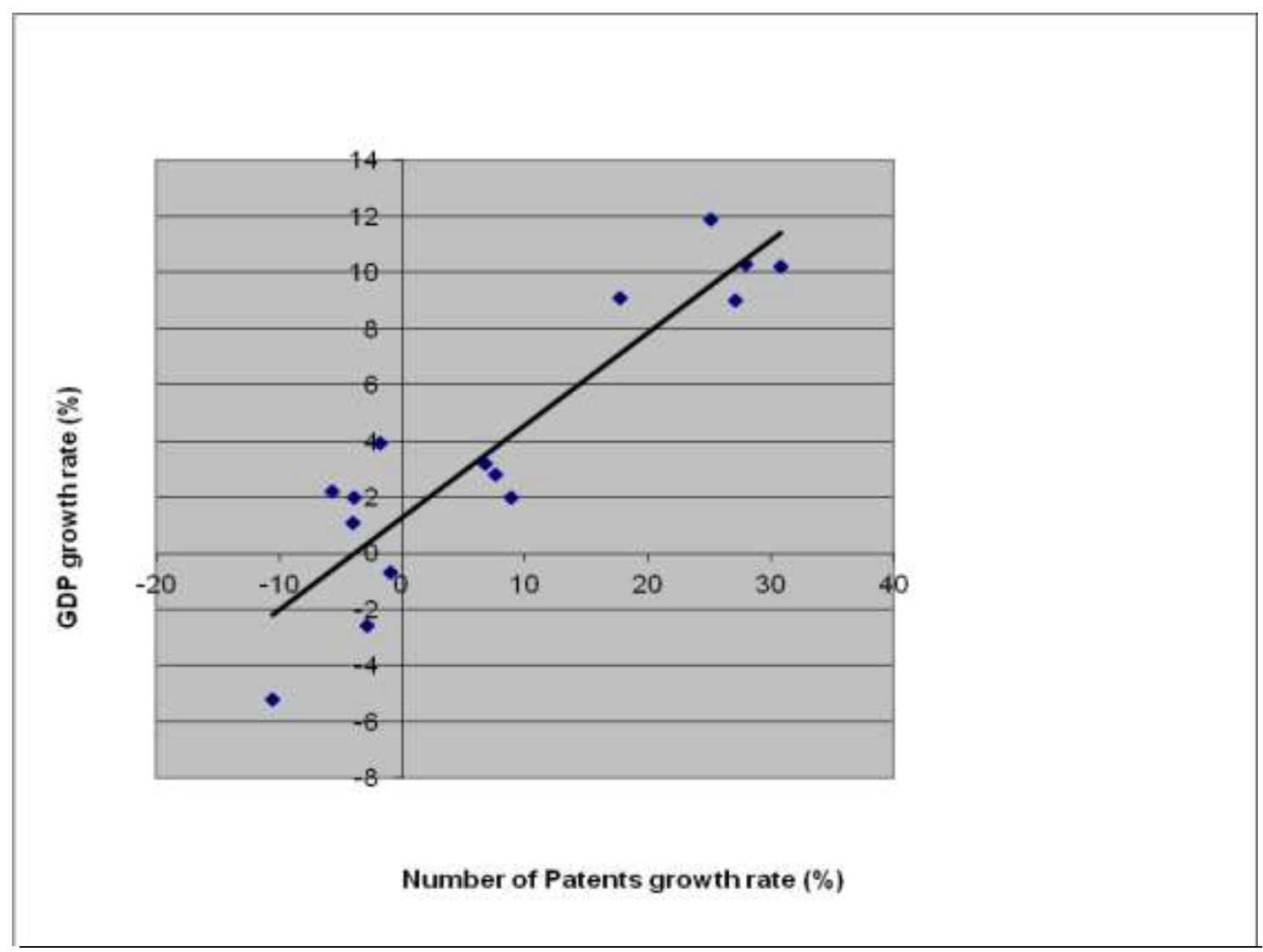

Figure 3

Scatter plot for the GDP growth rate and Patents growth rate, 2006-2010

One consideration in determining whether a parametric or a nonparametric (Pena-Sanchez, 2005) method should be used is the set of assumptions about the population probability distribution from which the data was obtained. For example, if we are using a parametric technique (Cooper and Schindler 2008), then the 'response' variable must be normally distributed at each population; moreover, two other required assumptions are: the observations represent independent random samples from the populations under study; and the variance of the response variable must be the same for such populations, this last assumption is called 'homoscedasticity'.

In order to avoid any risk imposed by the parametric techniques if their assumptions are not valid, we decided to use a nonparametric statistical method to test the null hypotheses; the analysis was developed through the Spearman's rank correlation test (Conover, 1999).

Table 4

Spearman's Rank Correlations Matrix (Coefficient / p-value (2-tailed) / n)

\begin{tabular}{|l|c|c|c|}
\hline & $\begin{array}{c}\text { Number of Patents Growth } \\
\text { Rate (\%) }\end{array}$ & $\begin{array}{c}\text { GDP Growth } \\
\text { Rate (\%) }\end{array}$ & $\begin{array}{c}\text { External Debt } \\
\text { (Billion US\$) }\end{array}$ \\
\hline Number of Patents Growth & 1 & $.804^{* *}$ & $-.614^{*}$ \\
Rate (\%) & & .0001 & .015 \\
& & 15 & 15 \\
\hline GDP & & 1 & $-.753^{* *}$ \\
Growth & & & .0001 \\
Rate (\%) & & 15 \\
\hline External Debt & & 1 \\
(Billion US\$) & & & 1 \\
\hline
\end{tabular}

**. Correlation is significant at the 0.01 level (2-tailed).

*. Correlation is significant at the 0.05 level (2-tailed). 


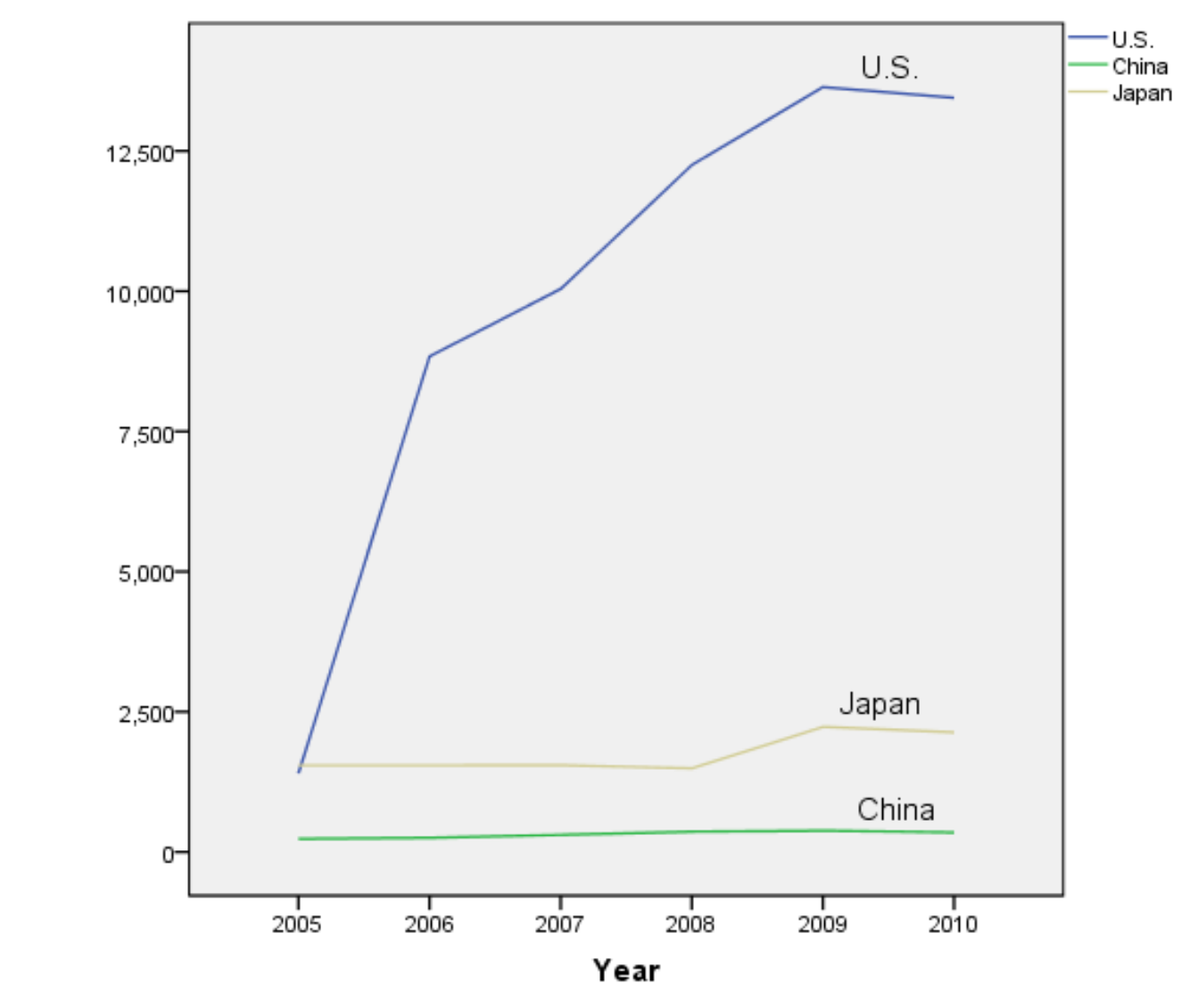

Figure 4

External Debt (Billion US\$) per Country

Data Source: http://www.indexmundi.com/g/g.aspx?v=94\&c=us\&l=en

"The external debt in US\$ billions represents the total public and private debt owed to nonresidents repayable in foreign currency, goods, or services. These figures were calculated on an exchange rate basis, i.e., not in purchasing power parity (PPP) terms". Source: $\underline{\mathrm{http}: / / \mathrm{www} . \text { indexmundi.com/g/g.aspx? } \mathrm{v}=94 \& \mathrm{c}=\mathrm{us} \& \mathrm{l}=\mathrm{en}}$ 


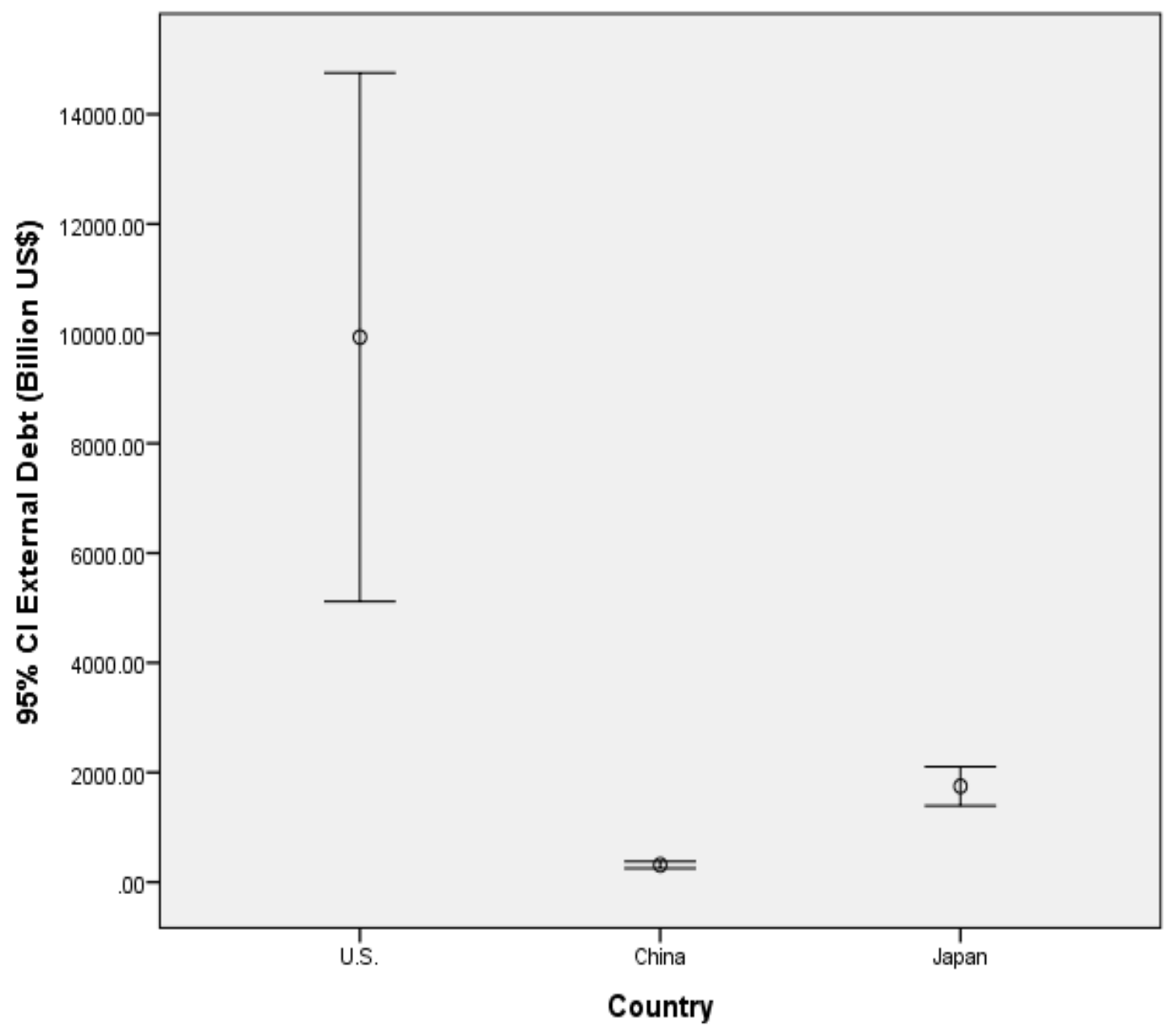

95\% Confidence Interval for the Mean External Debt (Billion US\$) per Country

\section{DIRECTIONS FOR FURTHER RESEARCH}

These findings should influence public (governmental) and private authorities responsible of research and development programs to design less bureaucratic and collaborative strategies that really motivate the production of patents. As educators and researchers, we all should seek the most effective and efficient tool (Jones. and Madden, 2002) for basic academic competences, as well as for collaborative tasks (McEntee and Pena-Sanchez, 1997).

It is hoped that this paper will foster more research into the relationships (Hilton, 1999) between governmental policies, technological tools, social environment, intellectual capital and the generation of patents; so that more effective and efficient decisions will occur both in public and private organizations whose agendas include research and development (Sitkin, Sutcliffe and Barsios-Choplin, 1992); for example, the organizational culture (Deem, Barnes, Segal and Preziosi, 2010) as part of the social environment plays a critical factor in the motivational aspect.

\section{DISCUSSION AND CONCLUSIONS}

There are several factors involved in the generation of patents: a) Signal factors (technological tools), b) Control factors (governmental policies), and c) Noise factors (social environment) that affect the generation of patents, which can be converted in a sustainable process (Rusinko, 2005). 
It is clear that China has been planning a policy to stimulate its technological development to pass from being a poor economy to one of maquila or maquiladora based economy, and subsequently to be positioned as one of technological innovation (Wang, Ahlstrom, Nair and Hang, 2008) with high levels of incomes. From a global point of view, the group conformed by USA, China, and Japan is the cluster of countries with the biggest production of patents; below this cluster appears South Korea (Republic of Korea), whose registration of patents is enumerated as 131,805 for the year 2010, below South Korea appears Germany with 47,047, and downward is the Russian Federation during the same year 2010 with 28,722 registered resident regional patents (WIPO, 2011).

A graphical tool used to explore the linear and nonlinear relationship among the two variables involved in the Research Hypothesis is provided by the scatter diagram in Figure 3; which indicates a positive linear correlation. Our conclusion supported by a nonparametric (Conover, 1999) statistical method through the Spearman's rank correlation test (p-value $<0.01$ on Table 4) permits the rejection of the null hypothesis; thus, we can conclude that there is a significant correlation at the 0.01 level between the GDP growth rates and the growth rates of the number of patents produced by the cluster of countries (U.S., China, and Japan) with the leadership in this activity during period 2005-2010.

About the linear long-term trend of the data in Figure 2: Japan shows a decreasing tendency; while the opposite behavior is shown by China with an increasing tendency about the production of patents; Figure 2 is a graphical representation of the data in Table 1 (Pena-Sanchez, 2012).

According to numerical-data in Figure 2, from 2005 until 2008: USA appears in the middle position between China and Japan, later on during 2009 and 2010 China was exceeding to USA; then, we can understand the pressure from above and from below; thus, this pressure may be transferred to organizations and their researchers in the form of competitiveness; at this point will be very relevant to define an appropriate methodology (criteria) for the distribution of economic resources to support to those researchers that have a compromise with the generation of patents that really represent tangible benefits.

Figure 5 contains a transformation of the external debt data given on Figure 4; this variable (the external debt) had been showing significant negative-correlations (Table 4) with the Number of Patents Growth Rate as well as with the GDP growth rate. It is evident the volume of complexity associated to the practically non-payable external debt of U.S. in comparison to the other two countries: China and Japan, whose external debts belong to another economical dimension. In case of U.S., since 2004 its external debt has been growing and reaching an unsuspected upper extreme limit. On June 30, 2011, the U.S.A. was occupying the second worldwide place with respect to its external debt: $\$ 14,710,000,000,000$ US-dollars, which was representing $103 \%$ of its GDP; meanwhile, the external debt first worldwide place corresponds to the block of European countries; in other words, on June 30, 2011 the external debt of the European Union had been registered as $\$ 16,080,000,000,000$ US-dollars. (Source: http://en.wikipedia.org/wiki/List_of_countries_by_external_debt)

\section{AUTHOR INFORMATION}

Rolando Pena-Sanchez is an Associate Professor of Decision Sciences in the Division of International Business and Technology Studies at Texas A\&M International University. His research interests include: Multivariate parametric and nonparametric statistical methods applied to business administration and environmental risk management. His more recent research has appeared in the International Journal of Business Research, the Journal of Business \& Economics Research, the Journal of Border Educational Research, as well as in the Journal Advances in Competitiveness Research. Contact: Rolando Pena-Sanchez, Ph.D., Texas A\&M International University, TX USA. E-mail: rsanchez@tamiu.edu

\section{REFERENCES}

1. Close, R. C., Humphrys, R. and Ruttenbur, B. W. (March 2000). e-Learning and Knowledge Technology. SunTrust Equitable Securities report.

2. Clyde, Anne. (1999). The Traveler's Guide to E-Mail Access; Teacher Librarian. Oct 1999. 27(1), 64-66.

3. Conover, W. J. (1999). Practical Nonparametric Statistics, 3 Ed. John Wiley \& Sons. 
4. Cooper, D.R. \& Schindler, P. S. (2008). Business Research Methods, 10 Ed. McGraw-Hill.

5. Deem, J. W., Barnes, B., Segal, S. and Preziosi, R. (2010). The Relationship of Organizational Culture to Balanced Scoreboard Effectiveness. SAM Advanced Management Journal, 75(4), 31-39.

6. Glauser, M. (1984). Upward information flow in organizations: review and conceptual analysis, Human Relations. 37(1), 613-643.

7. Hilton, Thomas S.E. (1999). A model for internet-enhanced education systems derived from history and experiment. Journal of Computer Information Systems. 39(3). Spring 1999.

8. Jones, S. and Madden M. (2002). The Internet Goes to College: How Students are Living in the Future with Today's Technology. Pew Internet \& American Life Project. http://www.pewinternet.org/pdfs/PIP College Report.pdf

9. Kirschner, P. A., and Paasa, F. (2001). Web-enhanced higher education: a tower of Babel; Journal of Computers in Human Behavior. (17), 347-353. Issue 4, July 2001.

10. McEntee, E. and Pena-Sanchez, R (1997). The Learning Process of Cooperation by Reciprocity. Proceedings of the 15th Studies experiences exchange meeting upon education. Third Congress of Academic Quality. ITESM, Vol.1, 1997, pp.184 -188.

11. Pena-Sanchez, R. (2010). Radio Frequency Identification: A Technology for Continuous Improvement. International Journal of Business Research. IABE; Vol. 10, Number 3, pp 93-103.

12. Pena-Sanchez, R. (2012). USA, China and Japan: Excellence and Leadership in Production of Patents. Proceedings of the SAM Annual International Business Conference; TAMUCC. Society for Advancement of Management (SAM).

13. Pena-Sanchez, R. (2005). A Nonparametric Comparison of the Per Capita Yearly Economic Needs for the Water Supply in the USA-Mexico Border Region. International Business and Economics Research Journal. 4(6), 35-46.

14. Rusinko, Cathy A. (2005). Using Quality management as a Bridge to Environmental Sustainability in Organizations. SAM Advanced Management Journal, 70(4), 54-60.

15. Sitkin, S. B., Sutcliffe, K. M. \& Barsios-Choplin, J. R. (1992). A dual-capacity model of communications media choice in organizations; Human Communication Research. 18(1), 563-598.

16. Wang, L. C., Ahlstrom, D., Nair, A. and Hang, R.Z. (2008). Creating Globally Competitive and Innovative Products: China's Next Olympic Challenge. SAM Advanced Management Journal, 73(3), 4-15.

17. WIPO (2011). World Intellectual Property Organization. http://www.wipo.int/ipstats/en/ http://www.wipo.int/ipstats/en/wipi/ http://www.wipo.int/ipstats/en/statistics/patents/wipo_pub_931.html http://www.wipo.int/export/sites/www/freepublications/en/intproperty/941/wipo_pub_941_2011.pdf 


\section{NOTES}

